\title{
Investigating relationships between the usage of Mathematics Learning Support and performance of at-risk students
}

\author{
Emma Berry, Ciarán Mac An Bhaird and Ann O'Shea* \\ Department of Mathematics and Statistics, National University of Ireland Maynooth, Co. Kildare, Ireland \\ *Email: ann.oshea@nuim.ie
}

[Submitted June 2014; accepted March 2015]

\begin{abstract}
The provision of some level of Mathematics Learning Support is now commonplace in the majority of Higher Education Institutions in the UK and Ireland. Most of these supports were initially established with the aim of trying to address the problem of large numbers of first-year students with weak mathematical backgrounds. The centres provide students the opportunity to overcome mathematical issues in their transition from school to Higher Education. This article presents findings from a recent quantitative study at a university, where the range of supports available and levels of engagement have increased dramatically since they were first offered in 2007. We investigated if the Mathematics Support Centre there was still helping the students who needed it most; in particular, we considered students' mathematical backgrounds, the number and length of their visits and their end of year module grades.
\end{abstract}

\section{Introduction}

The Mathematics Support Centre (MSC) at the National University of Ireland Maynooth (NUIM) has been in operation since 2007, and is available to all undergraduate students. The number of students availing the drop-in service provided by the MSC has grown very quickly in that time. For example, in the year 2012/13 there were 933 individual students registered at the drop-in sessions, this compares with 273 in 2007/8, 509 in 2008/9, 599 in 2009/10, 600 in 2010/11 and 849 in 2011/12. Similarly, in 2012/13 the total number of attendances at the drop-in sessions was 14927 ; this compares with 2493 in 2007/8, 4647 in 2008/9, 7262 in 2009/10, 7898 in 2010/11 and 13895 in 2011/12. (Note that the majority of attendees are taking modules in mathematics, for example, in 2012/13 95\% and in 2011/12 94\% of attendees were students taught in the Department of Mathematics and Statistics. The other students are typically from subjects such as Economics, Finance, Psychology and Engineering. The number of students taking mathematics modules in the university has remained stable at about 1000 students over this time period. This number includes students at all levels from first-year undergraduates to postgraduate students.)

Analysis conducted in the early years of the MSC at NUIM provided strong evidence of a relationship between MSC attendance and succeeding in examinations and this relationship was particularly evident for students who, on entry to the university, were deemed to be at-risk of failing their first-year mathematics modules (Mac an Bhaird et al., 2009). First-year students are classified as 'at-risk' based 
on their mathematics results in the Leaving Certificate (LC) (the national high-stakes examination in Ireland which determines entry to university) and their score on a diagnostic test which is administered in the first week of term (Burke et al., 2012). The MSC was originally set up to help students with weak mathematical backgrounds and these students typically belong to the large First Science cohort which has 400 students, in 2012/13 36\% and in 2011/12 29\% of attendees were from First Science. However, as the figures above show, the MSC is now used by almost all mathematics students. Therefore, to maintain standards in our Mathematics Learning Support (MLS) provision, we wanted to investigate whether the group it was originally intended for were still using it and if they were still benefitting from it. It is important to note that the MSC is not viewed by either students or staff as a purely remedial service. In annual anonymous student evaluations, students report that they also come to the MSC in groups to work on material and share ideas, and the positive atmosphere in the MSC has been highlighted as a significant factor in its success. Other research at NUIM (Mac an Bhaird \& O'Shea, 2009) and elsewhere (Pell \& Croft, 2008) highlight that high achievers also use MLS regularly with the intention of improving their grades.

Since the MSC commenced operation we have collected the attendance details of students and for the last two academic years, we also collected data on how long students spent per visit in the MSC. We wanted to study the relationship, if any, between the duration of time spent at the drop-in sessions and student success. In addition, we were interested in whether the days of the week on which students attended were important. This kind of data has not been considered in any other published studies that we could find in this area. Indeed, the only data we could find that measured the length of student visits was an internal report for sigma carried out at the University of Lincoln in the 2011-2012 academic year (Daley \& Snowley, 2012). This report presented the distribution in the lengths of student visits but did not consider potential relationships with performance.

The main questions we want to investigate in this study are:

(a) Are the at-risk students using the MSC?

(b) In the case of the at-risk students, is there a relationship between attendance at the MSC and success in mathematics modules?

(c) Does the length of time spent in the MSC contribute to students' success?

\section{Literature review}

Research has shown that large number of students are entering Higher Education Institutions (HEIs) without the basic skills they require to cope with the mathematical demands of their courses (e.g. Rylands \& Coady, 2009; Lawson et al., 2012). This international problem, commonly referred to as the 'Maths Problem', is well documented. In Ireland, there is considerable research on this topic, for example, both Lynch et al. (2003) and Hourigan \& O'Donoghue (2007) report on various aspects of the problem including issues in both schools and HEIs. Commentators have asserted that the 'Maths Problem' is not just an issue for students taking mathematics courses, but it is also considered an impediment for students in science, technology and engineering and is a contributing factor to low enrolment and retention rates in these disciplines across a range of HEIs (OECD, 2003; Sutherland \& Dewhurst, 1999; Pell \& Croft, 2008). Indeed the issue goes beyond the Science Technology Engineering and Mathematics (STEM) subjects, with many non-STEM degree programmes now containing some mathematical or statistical elements (Lawson et al., 2003). There is also research which suggests that many students arrive at their HEI having chosen mathematics-intensive courses without realizing it (FitzSimons \& Godden, 2000), and when students arrive in their HEI, the range in the standards of teaching and class size can add to their problems (Lawson et al., 2003). 
The provision of MLS is one response that many HEIs have taken to try and address the 'Maths Problem'. MLS is normally defined as a facility offered to students in addition to traditional lectures and tutorials. The main aim of MLS is to provide students with the opportunity to overcome their mathematical difficulties in a non-judgemental and encouraging environment (Lawson et al., 2003). While MLS is usually available for all students, the emphasis is often placed on targeting first-year students as their mathematical issues need to be addressed as soon as possible after entering higher education (Hourigan \& O'Donoghue, 2007). Gallimore and Stewart (2014) describe a project at the University of Lincoln, where targeted support was provided to students based on the results of a diagnostic test. They reported improved retention and achievement data for the cohort of Engineering students in the study. They also saw differences in achievement between the students who had low scores on the diagnostic test but engaged with supports and those who had low diagnostic test scores but did not engage fully.

As outlined in the 2012 sigma report (Mac an Bhaird \& Lawson, 2012), MLS takes many different forms depending on the facilities available in individual HEIs and the students' needs. The most common form of MLS is the provision of a MSC, whose main aims are 'to address issues surrounding the transition to university mathematics and to support students' learning of mathematics and statistics across the wide variety of undergraduate courses that require an understanding of mathematical concepts and techniques'. (Matthews et al., 2012, p. 3).

Most HEIs in Ireland and the UK have increased their levels of MLS provision significantly in recent years. Perkin et al. (2012) gives an overview of the growth of the MLS sector in the UK, in 2004 $62.3 \%$ of 106 universities surveyed offered some form of MLS (Pell \& Croft, 2008; p. 168), in 2012, this had risen to $85 \%$ of those surveyed (Perkin et al., 2012). In 2008 in Ireland, 13 out of 20 HEIs surveyed provided MLS (Gill et al., 2008) and since then many of the remaining HEIs have provided some form of MLS. MLS is also available in HEIs in many other countries, for example, in Australia (MacGillivray, 2008). MLS is becoming a key part of the service that any student should expect to receive within a HEI and the growth in the number of HEIs offering MLS seemed to suggest that MLS is making a 'difference'. Practitioners of MLS quantify this 'difference' through appropriate evaluation.

The majority of research carried out in this area to date is largely of a quantitative nature and focuses on evaluating the impact of MLS by considering the success rate of students (MacGillivray \& Croft, 2011). Focusing on MSCs or drop-in services, research consistently suggests that there is a positive correlation between attendance and students' mathematics module grades, for example, at NUIM (Mac an Bhaird et al., 2009), at Robert Gordon University in Aberdeen (Patel \& Little, 2006) and at Loughborough University (Lee et al., 2008; Symonds, 2008). This research also shows that the majority of first-year students who availed of this support were categorized to be weak or 'at-risk' students and the results suggested that the support benefited these weak students and showed improved student retention.

However, these studies have also shown that a significant minority of students who are most in need of MLS do not avail of it and many researchers have begun to consider the type of student using MLS. For example, Pell \& Croft (2008) found that first-year Engineering students who received top grades were more likely to attend the MSC than those who failed or who just passed the module. Similar results have been reported in MacGillivray (2009) and at NUIM by Mac an Bhaird \& O'Shea (2009).

\section{Methodology}

The drop-in service of the MSC at NUIM is available for $22 \mathrm{~h}$ per week during term time (typically 24 weeks of the year); it also opens during mid-term breaks and study weeks before 
exams. Students can avail of the drop-in service at any time during opening hours, no appointment is necessary. Students are encouraged to attend and to seek help for any mathematicsrelated problems, the majority of attendees take service mathematical modules, but the MSC is available to all undergraduate students. Typically, first-year service mathematics students attend with queries on lectures notes, particularly regarding notation and the 'mathematics language' being used. All students enrolled in mathematics modules at NUIM submit a weekly assignment each Friday afternoon and they also use the venue as a place to work on their assignments (on their own or in groups). The tutors will assist them whenever they ask for help, but the students need to have attempted the material, have brought their attempts and all relevant material with them. The help provided typically involves explaining methods or concepts, and working through examples and notes from the lectures or coursebook. However, students are made aware that MSC tutors will not do their assignments for them, nor will they check solutions or tell students if their answer is correct. The attendance figures from all students of all years who use the MSC show that it is often busier on Thursdays and Fridays than it is earlier in the week.

The authors have access to students' records in both the Department of Mathematics and Statistics and the MSC. All students who attend the MSC fill out a registration form during their first visit; this form asks if they will consent to their records being anonymously used for research purposes. The full implications are explained to each student by the staff member at reception. At the beginning of any subsequent visit, each student is issued with an attendance form which records their time of entry. This form is brief; students fill out their name, student number, the course that they are taking and the date. There is also space for comments on any aspect of the MSC. Students return these forms when they leave, or they are collected at the end of the session and the end time of the visit is recorded. These data are subsequently entered into an electronic file; there is a different file for each class group.

At the end of the academic year, all the electronic MSC data is collated along with the students' module results, their tutorial attendances and assignment grades. The students' diagnostic test scores and their LC results (which they provide on their diagnostic test answer sheet) are also entered. The diagnostic test deals with basic mathematical material and consists of 20 multiple-choice questions; three marks are awarded for a correct answer and minus one for an incorrect answer. Students who receive a grade (out of a maximum of 60) of 20 or less are deemed to have failed and are categorized as at-risk. Also, students with a LC mathematics mark of Ordinary Level (OL) B or lower are also categorized as at-risk. Mathematics can be taken at one of three levels in LC, however, only passing grades (A, B, C, D) in OL and Higher Level (HL) are acceptable for matriculation. Points are awarded in each subject taken in the LC examination, these points range from 0 to 100 depending on the level and grade (see http://www.cao.ie/handbook.php?page=19).

Each summer the data are analysed using SPSS, for example (as in this article), we compare the grades of students with similar mathematical backgrounds but who have different levels of engagement with mathematics and the MSC. In particular, we focus on at-risk students. All individual identifying characteristics are removed and then we provide a brief internal report, which includes both the outcomes of this analysis and the outcomes of the analysis of a separate anonymous MSC questionnaire. A summary of these results are also presented to students at the start of the following academic year.

\section{Results}

We will consider the data relating to the First Science cohorts of 2011/12 and 2012/13. 
TABLE 1. Attendance figures for 2011/12

\begin{tabular}{lclc}
\hline At-risk category & Attended once or less & Attended more than once & Total \\
\hline Not at-risk & 86 & 126 & 212 \\
At-risk & 58 & 111 & 169 \\
Total & 144 & 237 & 381 \\
\hline
\end{tabular}

TABLE 2. Attendance figures for 2012/13

\begin{tabular}{llll}
\hline At-risk category & Attended once or less & Attended more than once & Total \\
\hline Not at-risk & 60 & 169 & 229 \\
At-risk & 31 & 127 & 158 \\
Total & 91 & 296 & 387 \\
\hline
\end{tabular}

\subsection{Overview of the class groups}

There were 416 students in the First Science cohort in 2012/13 and 381 in the same group in 2011/12. In 2011/12, 169 students (44.4\% of the year group) were deemed to be at-risk; in 2012/13 the number of at-risk students was slightly less at 158 (38\% of the year group). There were 29 students in 2012/13 for whom we did not have enough data to decide whether they were at-risk or not.

\subsection{Attendance patterns}

In 2011/12, there were 3942 individual visits from First Science students to the MSC, of these 2068 were from at-risk students. The corresponding figures for 2012/13 were 5268 visits, of which 2400 were from the at-risk group. Tables 1 and 2 show the numbers of at-risk and not at-risk students who attended the MSC in 2011/12 and 2012/13. In both years, whether a student attended the MSC or not was found to be independent of whether they were deemed to be at-risk or not.

However, if we consider the number of times that a student attended the MSC and the amount of time they spent there, we do see differences in the behaviour of the two groups. There was evidence that the distribution of the number of visits to the MSC was not the same for the at-risk and not at-risk groups in 2012/13 (Mann-Whitney $U$ test, $p=0.018$ ). Figure 2 indicates that on average the at-risk students that year attended more often than their colleagues. Even though the mean and median values for the at-risk students in 2011/12 are greater than those for the not at-risk group that year, there is only slight evidence of a difference between the at-risk and not at-risk groups (Figure 1; Mann-Whitney $U$ test, $p=0.06$ ).

We found that for both years, the distribution of the time spent in the MSC was not the same for the at-risk and the not at-risk groups (Mann-Whitney $U$ test, $p=0.017$ in 2012/13, $p=0.012$ in 2011/12), with the at-risk students in both years attending for longer (Table 3).

We also considered the time of the week when students attended the MSC. As noted earlier, overall attendance figures for all years indicate that the MSC is generally busier on Thursday and Fridays, so we grouped the first-year science students into those who spent more time in the MSC early in the week (Monday to Wednesday) and those who spent more time in the MSC later in the week (Thursday and Friday). Note that we only considered students who had attended the MSC at least twice. We 


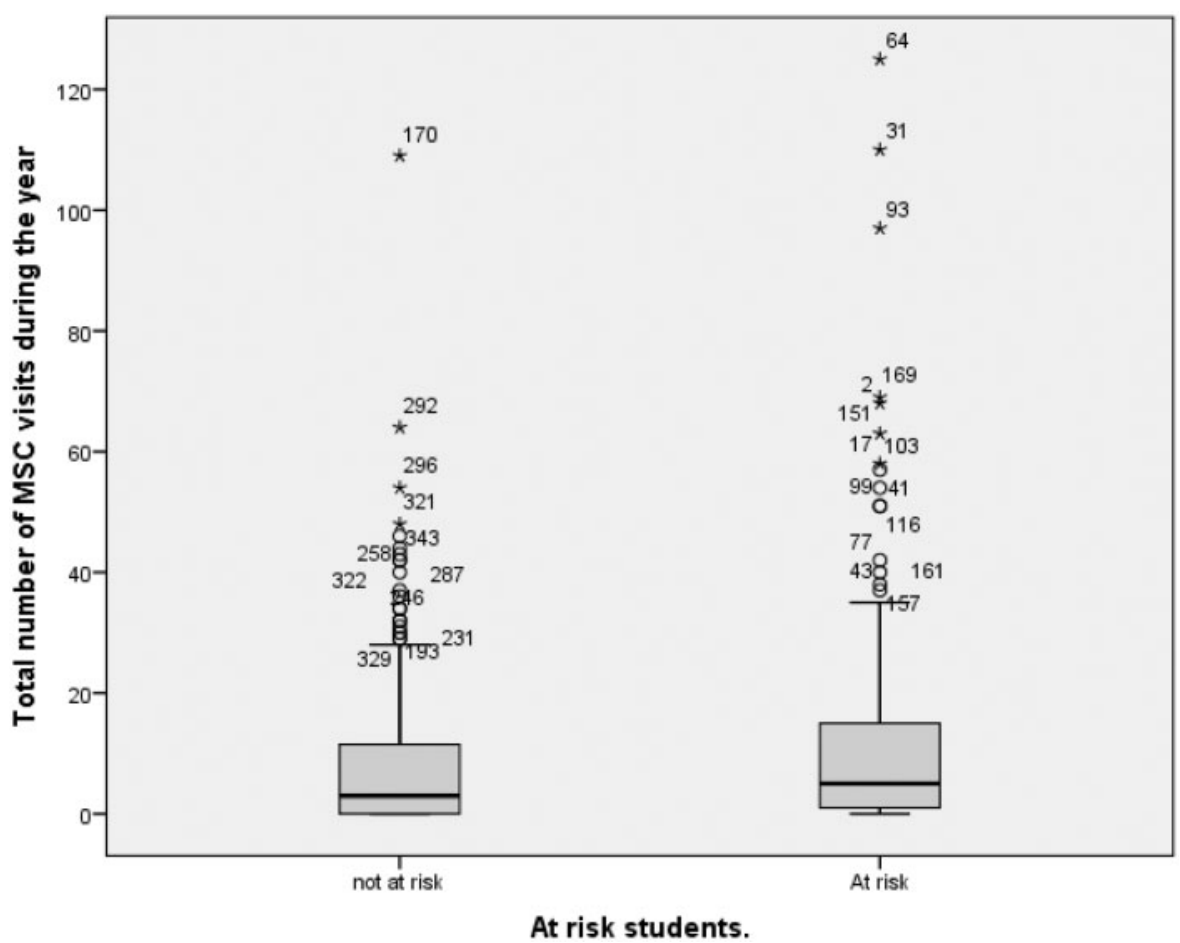

FIG. 1. Number of visits to MSC in 2011/12.

found that in 2012/13, the at-risk students were less likely than the not at-risk students to spend more time in the MSC later in the week (chi-square test: $p=0.046$ ). In fact, the majority of both groups of students spent more time in the MSC early in the week, rather than on Thursdays and Fridays (82.8\% of the at-risk students and $73.6 \%$ of the not at-risk students spent more time in the MSC early in the week). The MSC is usually busier later in the week; this indicates that students who are not in firstyear science tend to come later in the week.

\subsection{Relationship between attendance and grades}

In this part of our analysis, we will only consider those students who sat for the final examinations. In 2011/12, 340 First Science students including 146 at-risk students took the examinations; the numbers for 2012/13 were 384 and 140, respectively.

A multiple-regression analysis was carried out to investigate the relationship between at-risk students' first-year mathematics score and their LC points score, their diagnostic test score, the number of visits they made to the MSC and the number of minutes in total that they spent there. Each of the predictor variables had a significant correlation (at the 0.05 level) with the Overall Result variable. The suitability of using this model was also assessed using residual analysis.

We found that LC points, diagnostic test scores and the number of MSC visits were predictors of the final mathematics score in 2012/13 (with an $R^{2}=0.156$ ), whereas the predictors in 2011/12 were LC points, diagnostic test score and the time spent in the MSC $\left(R^{2}=0.397\right)$. In both models, the MSC variables had positive coefficients. The variables representing the number of MSC visits and the time 


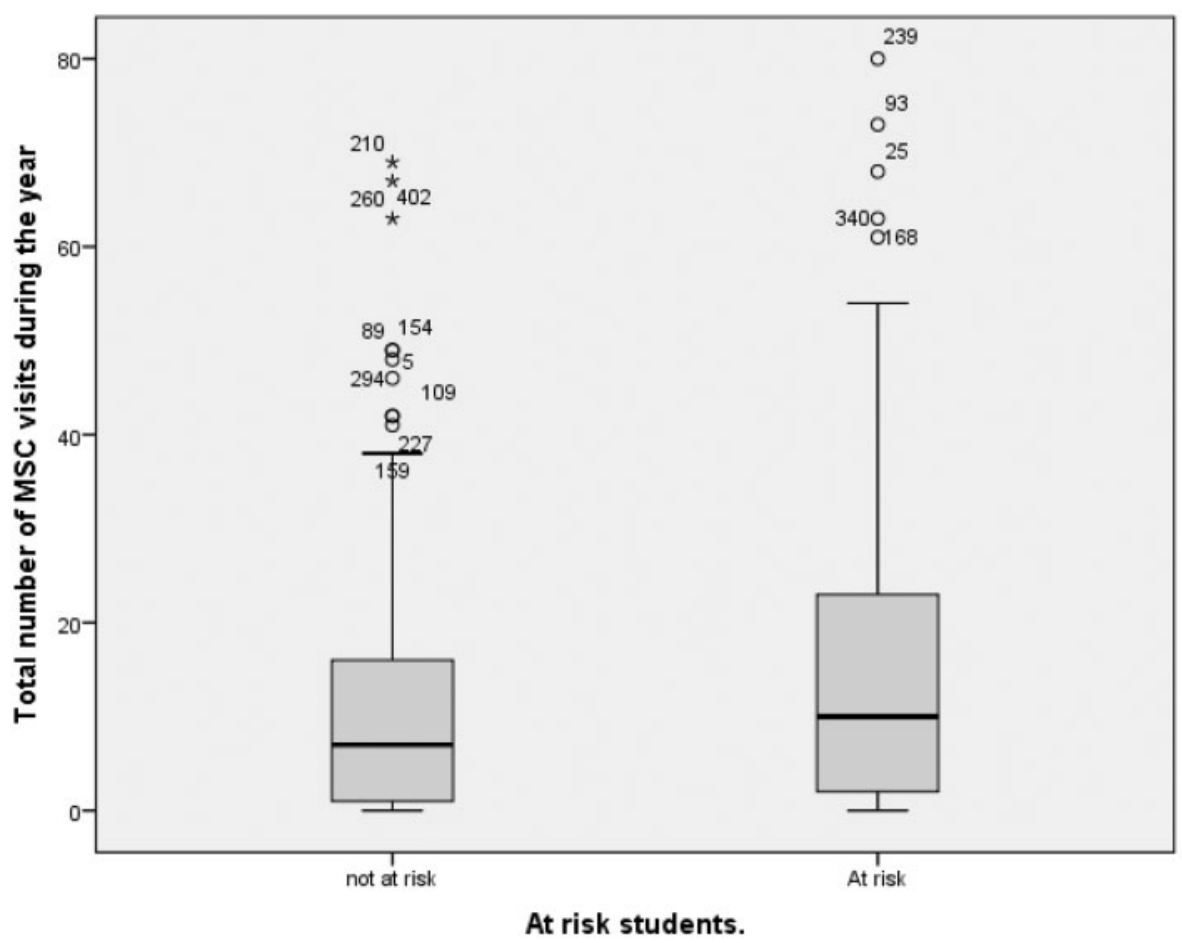

FIG. 2. Number of visits to MSC in 2012/13.

TABLE 3. Hours spent in MSC

\begin{tabular}{lcc}
\hline Group & Mean & Median \\
\hline At-risk 2011/12 & 15.72 & 5.25 \\
Not at-risk 2011/12 & 10.52 & 2.92 \\
At-risk 2012/13 & 19.36 & 11 \\
Not at-risk 2012/13 & 13.86 & 7.92 \\
\hline
\end{tabular}

spent in the MSC are very highly correlated, as would be expected. In both cases, the independent variables do not explain the majority of the variance in the overall mathematics score.

In an attempt to gain further insight a two-step cluster analysis was carried out using the variables mentioned above for each of the years 2011/12 and 2012/13 using the two-step clustering method. In 2011/12, the at-risk students were grouped into three clusters. The first cluster comprised students who had a medium level of attendance at the MSC, had relatively high scores on the LC and diagnostic tests, and the mean overall mathematics result was significantly higher than that of Cluster 3 but not that of Cluster 2. Cluster 2 consisted of students with a high level of attendance at the MSC, relatively low mean scores on the LC and diagnostic tests compared to Cluster 1, and higher overall mathematics marks on average than those of Cluster 3. Cluster 3 consisted of students with low attendance levels at the MSC, low scores on the LC and diagnostic tests and low grades on the overall mathematics mark. (All differences above were found to be significant at the 0.05 level using the Tamhane T2 test.) In 
2012/13, we found two clusters: the students in the first cluster had significantly higher mean scores on the overall mathematics mark, the number of MSC visits, the length of time spent in the MSC and the diagnostic test (one-way Analysis of Variance (ANOVA), $p<0.001$ for all variables); the mean LC points were not significantly different for Clusters 1 and $2(p=0.806)$.

We had conjectured that the first-year science students who attended primarily on Thursdays and Fridays would not be as successful as those who attended earlier in the week; however, we did not find any evidence for this. In fact, the proportion of students who successfully passed the end-of-year examinations in 2012/13 was independent of whether the student spent more time in the MSC early in the week (chi-square test: $p=0.75$ for the at-risk group, $p=0.634$ for the not at-risk group).

\section{Discussion}

In this article, we investigated if there was a relationship between overall mathematics marks of First Science students for the past two academic years and their levels of engagement with the MSC. In particular, we focused on students who were deemed at-risk of failing or dropping out of university because of their mathematical backgrounds as these students are the main target of MLS (Hourigan \& O'Donoghue, 2007). The motivation for this research was the considerable growth of the MSC at NUIM; we wanted to determine if it was still being used by at-risk students and if there was evidence to suggest that attendance at the MSC was still associated with a significant difference to their grades (Mac an Bhaird et al., 2009). Green and Croft (2012, p. 13) observe that '( $p$ )roving irrefutably that support has prevented drop-out (usually through averting failure) is very difficult to achieve', however, this type of quantitative evaluation is crucial to the effective running of an MSC (Matthews et al., 2012, p. 3) and it directs us in how to target our resources effectively subject to the constraints of the constantly changing student timetable and the availability of funding and a sufficient number of suitable tutors.

Our first main question of interest was whether at-risk students were still availing of the MSC. We found that at-risk students were more likely to attend and stay for longer than those who were deemed to be not at-risk. This is consistent with our previous research (Mac an Bhaird et al., 2009) and research elsewhere, for example, (Lee et al., 2008). We also considered the average duration of time the students spent per visit, something that has not been previously considered in related literature, and we found that on average, in 2012/13 at-risk students spent longer per visit in the MSC than not at-risk students. These results, while not unexpected, are encouraging and suggest that despite the general increase in use of the MSC, the target groups are still availing of the service.

We also considered the time of the week that students attended the MSC. We found that the at-risk students were less likely to spend more time in the MSC later in the week when the MSC is busier. We did not find any evidence of a relationship between the success of students and the time of the week when they preferred to attend.

Our second question concerned the relationship between attendance at the MSC and success in mathematics modules for at-risk students. The results indicate that at-risk students who attend MSC do better on average than those who do not, which again is consistent with our previous results (Mac an Bhaird et al., 2009) and results elsewhere, for example (Patel \& Little, 2006). In addition, for the at-risk groups, we carried out regression analysis which showed that their LC points, diagnostic tests scores and either the number of their MSC visits (2012/13) or the time they spent in the MSC (2011/ 12) were predictors of their final mathematics grade. However, these variables did not explain the majority of the variance in the overall mathematics grades. This indicates that although students' mathematical background and engagement with support are important, the situation is complicated 
and there are other factors that lead to student success. This, again, is consistent with other research (Lawson et al., 2003; Mac an Bhaird et al., 2009) which warns that MSCs cannot take full credit for impact on student grades as a number of factors are in play when it comes to student progress such as motivation, etc.

To gain a better understanding of the results of the at-risk students, we carried out a two-step cluster analysis. As a result of this analysis, both year groups were divided into smaller subgroups (three for 2011/12, two for 2012/13). The subgroup which performed least well in both years on average demonstrated very low engagement with the MSC, and very weak mathematical backgrounds (when compared to the other subgroups). This echoes the findings of Gallimore and Stewart (2014), who saw differences between at-risk students who engaged with support and those that did not and is a significant outcome for the operation of the MSC. The MSC still appears to be making a difference, but the categorization of students as being either at-risk or not at-risk, which we have used since we started in 2007, seems to be no longer sufficient. In the coming academic year, we will consider breaking the at-risk students into smaller subgroups, in attempt to better identify and address the specific needs of these students. This will not be straightforward; previously we have introduced additional interventions for at-risk students, for example, a peer-mentoring scheme (Burke et al., 2012), and these have had limited success. However, we have also introduced a scheme which monitors, on a weekly basis, student assignment submission and tutorial attendance (Burke et al., 2013), and this has seen a significant increase in student engagement. We hope to extend this scheme in the coming year to also monitor students' attendance at the MSC, and thus identify at-risk students with low levels of engagement earlier in the academic year.

Our third area of interest was whether the duration of time at-risk students spent per visit to the MSC was significant. This has not been considered in any previous research that we could find. We found that both the pass rates and mean mathematics marks for at-risk students who spent $26 \mathrm{~h}$ or more in the MSC were significantly higher than for those who spent less time there. Again, these results are not surprising but are encouraging in terms of the effectiveness of the MSC for at-risk students. However, as we have noted in previous work, for example, Mac an Bhaird et al. (2009), the factors which determine success in university are many and varied, and we do not claim that attendance at the MSC alone guarantees success. It may well be that, for example, the students who attend the MSC also study more than the students who do not attend and this is the reason that attendance seems to affect performance on examinations.

The outcomes in our three areas of interest are positive and will be reported to both the relevant authorities within our university and to our students. However, as outlined elsewhere, for example, Mac an Bhaird et al. (2009), Symonds (2008), a significant minority of at-risk students are still not availing of the MSC and at-risk students are still not doing very well overall. This is a common issue, as outlined by Lawson et al. (2003) who suggest that while MLS is a way of addressing the Mathematics Problem it is important to state that Mathematics Support Centres are not panaceas that will solve every difficulty associated with "the Mathematics Problem", (Lawson et al., 2003, p. 19). In NUIM, we have established a number of additional initiatives in an effort to increase student engagement with mathematics and MLS, particularly among at-risk students, for example, the peermentoring scheme as outlined above (Burke et al., 2012). We have found that these initiatives make a difference for students who use them appropriately, but there are still students who do not engage.

Several qualitative studies have investigated the reasons for student non-engagement with MLS and mathematics, for example, Grehan et al. (2011) at NUIM and Symonds (2008). These studies have highlighted that fear is a major factor in preventing students from engaging, but also that this is a very complicated area of research, and other issues such a social interactions, motivation, dealing with the transition to university also appear to be of central importance. 
The MSC attendance rate for first-year science students is very high with the majority of students attending the centre at least once. This is coupled with high rates of tutorial attendance for these groups. The centre is used by students who are struggling, as well as by those that are striving to get very high grades (Mac an Bhaird \& O'Shea, 2009) and is not seen by staff or students as separate from the other supports provided by the department. It may be that this is not the norm for such centres and does not fit the usual pattern of learning support, however, our experience suggests that integration of supports within academic disciplines can benefit students.

\section{REFERENCES}

Burke, G., Mac An Bhaird, C. \& O'Shea, A. (2013) The effect of a monitoring scheme on tutorial attendance and assignment submission. Int. J. of Math. Educ. Sci. \& Tech., 44, 545-553.

Burke, G., Mac an Bhaird, C. \& O'Shea, A. (2012) Peer mentoring for at-risk students. Proceedings of the CETL-MSOR Conference 2012 Sheffield (P. ROWLETT, D. WALLER, eds), MSOR Network, 9-14.

Daley, L. \& Snowley, I. (2012) Interim report on the mathematics \& statistics support. Internal Report for Sigma-network. Centre (MSSC) at the University of Lincoln, UK.

Fitzsimons, G. E. \& Godden, G. (2000) ) Review of research on adults learning mathematics. Perspectives on Adults Learning Mathematics: Research and Practice (D. COBEN, J. O’DONOGHUE \& G. E. FITZSIMONS eds) Dordrecht, The Netherlands: Kluwer Academic Publishers, pp. 13-45.

Gallimore, M. \& Stewart, J. (2014) Increasing the impact of mathematics support on aiding student transition in higher education. Teach. Math. Appl., 33, 98-109.

Gill, O., Johnson, P. \& O’Donoghue, J. (2008) An Audit of Mathematics Support Provision in Irish Third Level Institutions. Ireland: CEMTL, University of Limerick.

Green, D. \& Croft, T. (2012) Gathering student feedback on mathematics and statistics support provision: a guide for those running mathematics support centres. Report for Sigma, Coventry: Coventry University. (www.mathcentre.ac.uk/resources/uploaded/sigma-brochure-foraccfeb5-finalv1opt.pdf) [accessed 13 August 2014].

Grehan, M., Mac An Bhaird, C. \& O'SheA, A. (2011) Why do students not avail of mathematics support? Res. Math. Educ., 13, 79-80.

Hourigan, M. \& O'Donoghue, J. (2007) Mathematical under-preparedness: the influence of the pre-tertiary mathematics experience on students' ability to make a successful transition to tertiary level mathematics courses in Ireland. Int. J. Math. Educ. in Sci. \& Tech., 38, 461-476.

Lawson, D., Croft, T. \& Waller, D. (2012) Mathematics support past, present and future. Innovation, Practice and Research in Engineering Education. (http://www.academia.edu/2715773/Mathematics_support_past_ present_and_future) [accessed 1 August 2014].

Lawson, D., Croft, T. \& Halpin, M. (2003) Good practice in the provision of mathematics support centres. (http://www.mathcentre.ac.uk/resources/guides/goodpractic e2E.pdf) [accessed 1 August 2014].

Lee, S., Harrison, M., Pell, G. \& Robinson, C. (2008) Predicting performance of first year engineering students and the importance of assessment tools therein. Engineering Education, 3, 44-51.

Lynch, K., Lyons, M., Sheerin, E., Close, S. \& Boland, P. (2003) Inside Classrooms: A Study of Teaching and Learning, Dublin: Institute of Public Administration.

Mac An Bhaird, C., Morgan, T. \& O'Shea, A. (2009) The impact of the mathematics support centre on the grades of first year students at the National University of Ireland Maynooth. Teach. Math. Appl., 28, $117-122$.

Mac An Bhaird, C. \& O'SheA, A. (2009) What type of student avails of mathematics support and why? Proceedings of the CETL MSOR Conference 2009 (D GREEN ed.) 48-51.

Mac An Bhaird, C. \& Lawson, D. (2012) How to set up a Mathematics and Statistics Support Provision(http:// www.mathcentre.ac.uk/resources/uploaded/51691-how-to-set-upfinal.pdf) [accessed 1 August 2014]. 
Macgillivray, H. (2008) Learning support in mathematics and statistics in Australian universities - a guide for the university sector. Australian Learning and Teaching Council. (http://www.olt.gov.au/resource-learning-support-mathematics-guide-qut-2008) [accessed 1 August 2014].

MacGillivray, H. (2009) Learning support and students studying mathematics and statistics. Int. J. Math. Educ. Sci. \& Tech., 40, 455-472.

Macgillivray, H. L. \& Croft, A. C. (2011) Understanding evaluation of learning support in mathematics and statistics. Int. J. Math. Educ. Sci. \& Tech., 42, 189-212.

Matthews, J., Croft, T., Lawson, D. \& Waller, D. (2012) Evaluation of mathematics support centres: a review of the literature. (http://www.mathcentre.ac.uk/resources/ uploaded/52487-evaluation-of-msc-7.pdf) [accessed 1 August 2014].

Organisation For Economic Co-Operation And Development (OECD) (2003) Learning for Tomorrow's World - First Results from PISA 2003. Paris: OECD.

Patel, C. \& Little, J. (2006) Measuring maths study support. Teach. Math. Appl., 25, 131-138.

Pell, G. \& Croft, T. (2008) Mathematics support - support for all? Teach. Math. Appl., 27, 167-173.

Perkin, G., Lawson, D. \& Croft, T. (2012) Mathematics learning support in higher education: the extent of current provision in 2012. (http://www.mathcentre.ac.uk/resources/uploaded/52789-mls-in-uk.pdf) [accessed 1 August 2014].

Rylands, L. J. \& CoAdy, C. (2009) Performance of students with weak mathematics in first-year mathematics and science. Int. J. Math. Educ. Sci. \& Tech., 40, 741-753.

Sutherland, R. \& Dewhurst, H. (1999) Mathematics Education Framework for Progression from 16-19 to HE, Bristol: University of Bristol Graduate School of Education.

Symonds, R. (2008) Evaluating Students' Engagement with Mathematics Support. Ph.D. Thesis, UK: Loughborough University.

Emma Berry is a tutor in the MSC and a PhD student in the Department of Mathematics and Statistics at the National University of Ireland Maynooth.

Ciarán Mac an Bhaird is Manager of the MSC and is a lecturer in the Department of Mathematics and Statistics at the National University of Ireland Maynooth.

Ann O'Shea is Director of the MSC and is a lecturer in the Department of Mathematics and Statistics at the National University of Ireland Maynooth. 